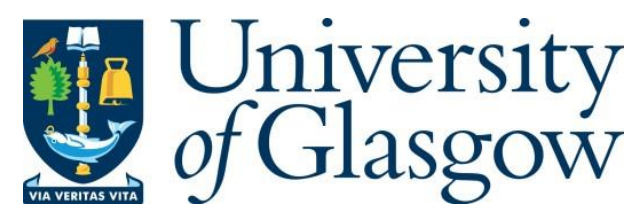

Al-Moathin, A., Ye, S., Watson, S., Di Gaetano, E., Al-Taai, Q. R. A., Eddie, I., Li, C., Hou, L., Kelly, A. and Marsh, J. H. (2021) Electroabsorption Modulated Laser Based on Identical Epitaxial Layer and Transmission Line Technology. In: CLEO/Europe-EQEC 2021, Munich, Germany, 21-25 Jun 2021, ISBN 9781665418768.

There may be differences between this version and the published version. You are advised to consult the publisher's version if you wish to cite from it.

https://eprints.gla.ac.uk/237678/

Deposited on: 29 March 2021

Enlighten - Research publications by members of the University of Glasgow https://eprints.gla.ac.uk 


\title{
Electroabsorption Modulated Laser Based on Identical Epitaxial Layer and Transmission Line Technology
}

\author{
Ali Al-Moathin ${ }^{1}$, Shengwei Ye ${ }^{1}$, Scott Watson ${ }^{1}$, Eugenio Di Gaetano ${ }^{1}$, Qusay Raghib Ali Al-Taai ${ }^{1}$, \\ Iain Eddie ${ }^{2}$, Chong Li ${ }^{1}$, Lianping Hou ${ }^{1}$, Anthony Kelly ${ }^{1}$, and John H. Marsh ${ }^{1}$ \\ 1. James Watt School of Engineering, University of Glasgow, Glasgow G12 8OQ, U.K. \\ 2. Sivers Photonics Ltd., Glasgow G72 OBN, U.K.
}

Low-cost solutions for delivering high communication bandwidths in both short- and long-haul systems are urgently required. Electroabsorption modulated lasers (EMLs), comprising a distributed feedback (DFB) laser and electroabsorption modulator (EAM), can address this. They are compact and offer a high modulation speed with low drive voltage, low chirp, and high extinction ratio [1]. To the best of our knowledge, the EAM in EMLs based on identical epitaxial layer technology has so far been configured with a lumped electrode. This can take the form of either a circular-pad, a rectangular-pad or the centre electrode of a ground-signal-ground (GSG) configuration. All result in a high capacitance, which in turn limits the modulation speed. Although the GSG choice has a similar configuration to that of a coplanar waveguide (CPW), it still behaves as a lumped electrode because of the lack of impedance matching. A planarized film of low- $k$ material can be used to reduce the capacitance, however standard methods such as Benzocyclobutene or polyimide-based planarization are very difficult to implement as they are incompatible with many photonic integration steps [2].

Here, for the first time, we present a new approach for fabricating an EML based on the identical epitaxial layer scheme. The structure is a $p-i-n$ separate confinement heterostructure grown in the AlGaInAs/InP system with an epitaxial structure described in [3]. The EML was initially integrated using a single 2.5- $\mu$ m-wide common ridge with a $30 \mu \mathrm{m}$ isolation section to separate the DFB and EAM electrically. The DFB used a first-order sidewall Bragg grating, $600 \mu \mathrm{m}$ in length with a central quarter-wavelength phase-shift. The EAM section was deepetched down to the heavily-doped substrate, then a 5 - $\mu$ m-thick planarizing film of hydrogen silsesquioxane (HSQ) was used as the low- $k$ material of a transmission line (TL) to integrate the electrode [2]. The planarized structure is shown in Fig. 1(a). Simulation, using HFSS [4], was used to design the EAM and optimise the TL configuration for the best impedance matching. The simulated $\mathrm{Y}_{11}$ parameter was used to calculate the EAM capacitance $(C)$, which was found to be $0.1486 \mathrm{pF}$, which indicates the $3-\mathrm{dB}$ cutoff frequency, $f_{-3 \mathrm{~dB}}=1 / 2 \pi R C$, is $21 \mathrm{GHz}$. Accordingly, a $160-\mu \mathrm{m}$-long EAM was integrated with an electrode formed of a combination of an 8 - $\mu \mathrm{m}$-wide microstrip preceded by a CPW of $60 \mu \mathrm{m}$ stripline width and $40 \mu \mathrm{m}$ signal-to-ground gap to provide a direct probe interface. The matching between the fabricated device and the design was checked by comparing the $S_{11}$ parameter from the simulation and experiment, as shown in Fig. 1(b). The electrical to optical (E/O) power response of the modulated signal was measured and the normalized plot is shown in Fig. 1(c), which indicates, at $-3-\mathrm{dBo}$, a modulation speed of $18 \mathrm{GHz}$ is achieved at a bias voltage of $-1.7 \mathrm{~V}$. The optical spectrum at a driving current of $160 \mathrm{~mA}$ is shown in Fig. 1(d), which indicates the operation wavelength was $1572 \mathrm{~nm}$.
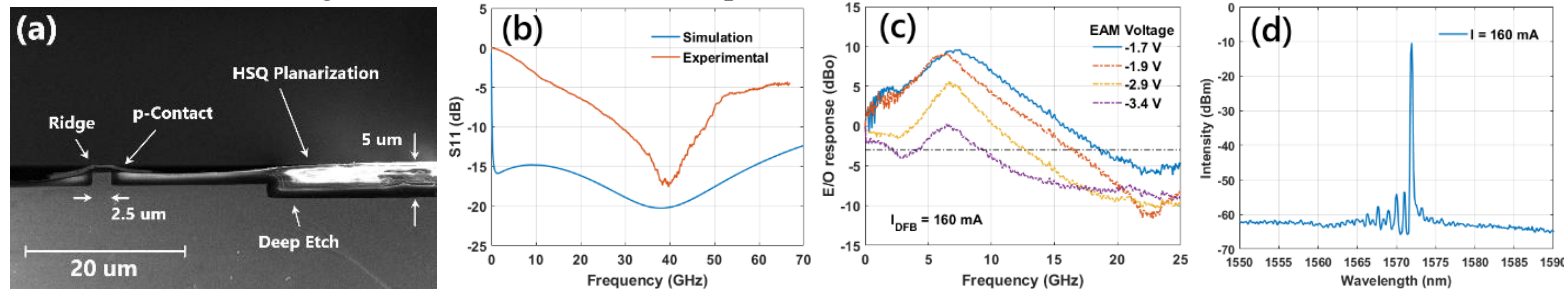

Fig. 1 (a) SEM-image of the device at the EAM section, (b) simulated and experimental results of the $S_{11}$ parameter,

(c) E/O response of the modulated signal, and (d) the optical spectrum at a DFB drive current of $160 \mathrm{~mA}$.

In summary, an EML has been designed and fabricated based on HSQ planarization, SWG, and TL technology. Experimental results are in good agreement with simulations in terms of the $S_{11}$ parameter and modulation speed. The laser exhibits stable operation free from mode hopping and has a side mode suppression ratio $>40 \mathrm{~dB}$. The new design approach provides an efficient solution for fabricating a high-speed EAM with a simple, regrowthfree, and low-cost process.

\section{References}

[1] M. Theurer, G. Przyrembel, A. Sigmund, W. D. Molzow, U. Troppenz, and M. Möhrle, "56 Gb/s L-band InGaAlAs ridge waveguide electroabsorption modulated laser with integrated SOA," Phys. status solidi, vol. 213, no. 4, pp. 970-974, 2016.

[2] A. Al-Moathin et al., "Thick film hydrogen silsesquioxane planarization for passive component technology associated with electronicphotonic integrated circuits," J. Vac. Sci. Technol. B, Nanotechnol. Microelectron., vol. 37, no. 6, p. 61210, 2019.

[3] A. Al-Moathin, L. Hou, E. D. Gaetano, and J. H. Marsh, "EML Based on Lumped Configuration, Identical Epitaxial Layer and HSQ Planarization," in 2020 International Conference on UK-China Emerging Technologies (UCET), 2020, pp. 1-4.

[4] ANSYS, "ANSYS HFSS: High Frequency Electromagnetic Field Simulation Software,” 2019. [Online]. Available: https://www.ansys.com/en-gb/products/electronics/ansys-hfss. [Accessed: 13-Mar-2019]. 